\title{
Neurogenic potentials of human amniotic fluid-derived stem cells according to expression levels of stem cell markers and ingredients of induction medium
}

\author{
Eun Hye Lim ${ }^{1,+}$, Jung Ah Cho ${ }^{1,+}$, Ho Park', Tae Jong Song ${ }^{2}$, Woo Young Kim², Kye Hyun Kim², and Kyo Won Lee ${ }^{1,2 *}$ \\ ${ }^{1}$ Adult Stem Cells Research Institute, \\ ${ }^{2}$ Department of Obstetrics and Gynecology, Kangbuk Samsung Hospital, Sungkyunkwan University School of Medicine, Seoul, Korea
}

\begin{abstract}
Purpose: We investigated the neurogenic potentials of amniotic fluid-derived stem cells (AFSCs) according to the expression levels of stem cell markers and ingredients in the neural induction media.

Materials and Methods: Four samples of AFSCs with different levels of Oct-4 and c-kit expression were differentiated neurally, using three kinds of induction media containing retinoic acid (RA) and/or a mixture of 3-isobutyl-1-methylxanthine/ indomethacin/insulin (neuromix), and examined by immunofluorescence and reverse transcription-polymerase chain reaction (RT-PCR) for their expression of neurospecific markers.

Results: The cells in neuromix-containing media displayed small nuclei and long processes that were characteristic of neural cells. RT-PCR analysis revealed that the number of neural markers showing upregulation was greater in cells cultured in the neuromix-containing media than in those cultured in RA-only medium. Neurospecific gene expression was also higher in Oct-4 and c-kit double-positive cells than in c-kit-low or -negative cells.

Conclusion: The stem cell marker c-kit (rather than Oct-4) and the ingredient neuromix (rather than RA) exert greater effects on neurogenesis of AFSCS.
\end{abstract}

Key words: Stem cells, Amniotic fluid, Neurogenesis.

\section{Introduction}

Stem cells have the ability to self-renew by producing equipotent progeny and to differentiate into a variety of cell types that make up each organ in the human body [1]. These stem cell properties have been studied for their application to repair damaged areas and injured tissues within the body [2-4]. Stem cells are generally divided into embryonic, adult, and fetal stem cells, the last of which can be obtained from fetal tissues, including amniotic fluid [5].

Analyses of human amniotic fluid have been used as safe and reliable screening tools for fetal genetic and congenital diseases for many years [6]. Amniotic fluid contains cells originating from both embryonic and extraembryonic tissues (amnion, placenta, fetus skin, and respiratory, gastrointestinal, and urinary tracts) during human development, displaying a heterogeneous cell

Received: 10 April 2015, Revised: 10 June 2015, Accepted: 17 June 2015, Published: 30 June 2015

*Corresponding author: Kyo Won Lee, M.D., Ph.D.

Adult Stem Cells Research Institute, Department of Obstetrics and Gynecology, Kangbuk Samsung Hospital, Sungkyunkwan University School of Medicine, 29 Saemunan-ro, Jongno-gu, Seoul 110-746, Korea.

Tel: +82-2-2001-2498, Fax: +82-2-2001-2187, E-mail: kw4773.lee@samsung.com

'These authors contributed equally to this work.

Conflict of interest: We declare that we do not have any conflicts of interests.

(c) This is an open-access article distributed under the terms of the Creative Commons Attribution Non-Commercial License (http://creativecommons.org/licenses/by-nc/4.0/) which permits unrestricted non-commercial use, distribution, and reproduction in any medium, provided the original work is properly cited.

c Copyright 2015 by the Korean Society of Medical Genetics 
population with a range of morphologies [7]. Amniotic fluidderived stem cells (AFSCs) were first isolated on the basis of their ability to adhere to plastic, and were characterized by their expression of mesenchymal cell surface markers (CD90 and CD105), a pluripotent marker (Oct-4), and an embryonic stem cell (ESC)-specific marker (stage-specific embryonic antigen-4 $[8,9]$.

AFSCs can be expanded and differentiated into adipocytes, osteocytes, and myocytes, as well as endothelial, hepatic, and neurogenic cells [2]. In addition, AFSCs have a high proliferative capacity and can be transplanted autologously without immunity-related problems and the ethical concerns associated with the use of ESCs. Furthermore, AFSCs do not form tumors in severe combined immunodeficient mice [2]. Implanted AFSCs can survive and migrate into the striatum of normal and ischemic rats, and express doublecortin, a marker for immature neurons at 10 days, and glial fibrillary acidic protein (GFAP), a marker for astrocytes at 10,30, and 90 days after transplantation [3]. These findings suggest that AFSCs could be a new cell source in therapies for nervous system pathologies in the future.

As a signaling molecule, the vitamin A derivative retinoic acid (RA) is involved in neuronal patterning and neural differentiation, and plays a role in generating specific neuronal cell types for therapeutic transplantation and in regenerating axons after damage [10]. RA is especially able to induce the differentiation of ESCs and embryonic carcinoma cells into neural cell types according to time and concentration $[11,12]$. Therefore, RA can be used as a therapeutic molecule for the induction of axon regeneration and the treatment of neurodegeneration [10].

Because AFSCs are at an intermediate stage between embryonic and adult stem cells [2], we tested whether the RA used in neurogenesis of ESCs can also influence the neurogenesis efficiency of AFSCs that express different levels of two representative stem cell markers, 0ct-4 and c-kit. Cells treated with RA were compared with cells treated with a neural induction cocktail containing 3-isobutyl-1-methylxanthine (IBMX), indomethacin, and insulin, which had previously induced adult stem cells from adipose tissue-derived stem cells (ADSCs) into having the morphology of neural cells and expressing neural markers.

\section{Materials and Methods}

\section{Isolation and culture of AFSCs}

Amniotic fluid was obtained by amniocentesis during the second trimester of gestation, and 18 AFSC types were isolated by the method of Kim et al. [13]. The Institutional Review Board of Kangbuk Samsung Hospital (Seoul, Korea) approved this study (IRB No. C0752).

\section{Reverse transcription-polymerase chain reaction (RT- PCR)}

Total cellular RNA was extracted from the cells using Trizol reagent (Invitrogen, Carlsbad, CA, USA), according to the manufacturer's instructions. The extracted total RNA was reverse-transcribed into first-strand cDNA using oligo-dT primers (Invitrogen) with moloney murine leukemia virus (MMLV) reverse transcriptase, RNasin ribonuclease inhibitor, $5 \times$ reaction buffer (Promega, Madison, WI, USA), and $2.5 \mathrm{mM}$ dNTP (Takara, Japan) for $90 \mathrm{~min}$ at $37^{\circ} \mathrm{C}$, followed by inactivation for 5 min at $75^{\circ} \mathrm{C}$ and cooling to $4^{\circ} \mathrm{C}$. The cDNA was amplified with 35 cycles of PCR using Taq polymerase (Takara). All primer pairs used for the PCR amplification are described in Table 1.

\section{Neurogenic differentiation}

Cells were plated in control medium in a 6-well dish. After 2 days, the medium was changed to one of three kinds of

Table 1. RT-PCR primer sequences and product sizes

\begin{tabular}{|c|c|c|c|}
\hline Gene & Primer sequence $\left(5^{\prime} \rightarrow 3^{\prime}\right)$ & $\begin{array}{l}\text { Product } \\
\text { size (bp) }\end{array}$ & $\begin{array}{l}\text { Annealing } \\
\text { temperature }\left({ }^{\circ} \mathrm{C}\right)\end{array}$ \\
\hline$\beta$-actin & $\begin{array}{l}\text { For : gcactcttccagccttccttcc } \\
\text { Rev : tcaccttcaccgttccagttttt }\end{array}$ & 515 & 50 \\
\hline Oct-4 & $\begin{array}{l}\text { For : cgtgaagctggagaaggagaagctg } \\
\text { Rev : caagggccgcagcttacacatggtc }\end{array}$ & 247 & 63 \\
\hline c-kit & $\begin{array}{l}\text { For : tgcctgttgtgtctgtgtcca } \\
\text { Rev : tgcctgttgtgtctgtgtcca }\end{array}$ & 534 & 64 \\
\hline GFAP & $\begin{array}{l}\text { For : gggaggcggccagttatcagga } \\
\text { Rev : ccagcagaggcggagcaactatc }\end{array}$ & 420 & 64 \\
\hline MAP2 & $\begin{array}{l}\text { For : tcagaggcaatgaccttacc } \\
\text { Rev : gtggtaggctcttggtcttt }\end{array}$ & 320 & 51 \\
\hline NSE & $\begin{array}{l}\text { For : atcgcgccagccctcatcagc } \\
\text { Rev : ttttccgtgtagccagccttgtcg }\end{array}$ & 500 & 62 \\
\hline NF-M & $\begin{array}{l}\text { For : ggaggaagacatccaccggc } \\
\text { Rev : gccggtactcggcgatctct }\end{array}$ & 452 & 65 \\
\hline trkA & $\begin{array}{l}\text { For : gcatccccttctctgtggat } \\
\text { Rev : agcaaggaagaccttcccaa }\end{array}$ & 665 & 55 \\
\hline MBP & $\begin{array}{l}\text { For : ccacacaccccaattagctg } \\
\text { Rev : cctgtgcctactcgctacca }\end{array}$ & 424 & 55 \\
\hline tau & $\begin{array}{l}\text { For : caactcaaagctcgcatggt } \\
\text { Rev : tcccctgattttggaggttc }\end{array}$ & 467 & 55 \\
\hline $\operatorname{RAR} \alpha$ & $\begin{array}{l}\text { For : gtacccggtgcctccctacg } \\
\text { Rev : cggcgtcagcgtgtagctct }\end{array}$ & 493 & 60 \\
\hline RAR $\beta$ & $\begin{array}{l}\text { For : tcagcgcctgtgagggatgt } \\
\text { Rev : gcggccttcagcagggtaat }\end{array}$ & 487 & 60 \\
\hline
\end{tabular}

RT-PCR, reverse transcription-polymerase chain reaction. 
neurogenic induction media (IM): IM1 consisted of control medium with $10^{-6} \mathrm{M}$ all-trans RA (Sigma, St. Louis, MO, USA), IM2 consisted of control medium with neuromix $(5 \mu \mathrm{g} / \mathrm{mL}$ insulin, $200 \mu \mathrm{M}$ indomethacin, and $0.5 \mathrm{mM}$ IBMX), and IM3 consisted of control medium with $10^{-6} \mathrm{M}$ all-trans RA plus neuromix. The cells were induced for 3 days.

\section{Immunofluorescence}

Cells, grown on coverslips in each medium described above, were fixed for $10 \mathrm{~min}$ in 4\% paraformaldehyde (Junsei Chemical Co. Ltd., Tokyo, Japan) in Dulbecco's modified phosphatebuffered saline (DPBS) at room temperature, and washed with $0.1 \%$ bovine serum albumin (BSA; Bovogen, Melbourne, VIC, Australia) in DPBS. This was followed by a 45 min incubation in blocking buffer (10\% normal goat serum [Gibco, Grand Island, NY, USA] and 0.3\% Triton X-100 [Sigma] in DPBS) at room temperature. The cells were then stained with a primary antibody at $4^{\circ} \mathrm{C}$ overnight, washed with $0.1 \%$ BSA-containing DPBS, and incubated with fluorescence-labeled secondary antibody at room temperature for 1.5 hours. Then, the cells were washed and counterstained with $0.1 \mu \mathrm{g} / \mathrm{mL}$ 4',6-diamino2'-phenylindole (Pierce, Rockford, IL, USA). Anti-GFAP (1:400; Dako, Glostrup, Denmark) and anti-Tuj1 (1:500; RetD Systems, Minneapolis, MN, USA) were used as primary antibodies, and Alexa Fluor ${ }^{\circledR} 488$ donkey anti-rabbit immunoglobulin $\mathrm{G}$ (IgG) $(\mathrm{H}+\mathrm{L}, 1: 400$; Invitrogen) and Cy3-goat anti-mouse lgG (1:400; Jackson Immunoresearch Laboratories Inc., West Grove, PA, USA) were used as secondary antibodies.

\section{Results}

\section{Stem cell marker expression of AFSCs}

With the isolation methods described above, we obtained AFSCs from 18 independent donors. First, the stem cell marker expression levels were examined by performing RT-PCR for Oct-4 and c-kit (Fig. 1). The AFSCs showed various levels of Oct-4 or c-kit expression, indicating that 0ct-4 and c-kit were expressed independently in these cells. For further experiments, we selected four independent AFSCs (AF1, AF16, AF17, and AF18) with different expression levels of Oct-4 or c-kit (viz., Oct- $4^{-} \mathrm{c}-\mathrm{kit}{ }^{\text {low }}$, Oct- $4^{+} \mathrm{c}-\mathrm{kit}{ }^{+}, 0 \mathrm{Oct}-4^{+} \mathrm{c}-\mathrm{kit}{ }^{\text {low }}$, and $0 \mathrm{ct}-4^{+} \mathrm{c}-\mathrm{kit}{ }^{-}$, respectively). $0 c t-4^{+} c-k i t^{\text {low }}$ and $0 c t-4^{+} c-k i t^{-}$cells were selected randomly.

\section{Neural differentiation potential of AFSCs}

To investigate the effect of RA on neural differentiation of AFSCs expressing different levels of Oct-4 and c-kit, the four selected AFSC samples were treated with three different kinds of neurogenic IM: IM1, IM2, or IM3, as described in Materials and Methods. AFSCs cultured in each of the neurogenic IM began to change their cell morphology within 24 hours. The cytoplasm retracted toward the nucleus, and long and thin cellular processes extended from the cell bodies. After the first day of induction, there were more retracted cells and shorter processes in IM1 than in IM2 and IM3. On the second day of induction, IM2 and IM3 had more morphologically altered cells, which had brightened nuclei, retracted cytoplasm, and developed processes. On the third day of induction, the number of neural-like cells was increased over the previous day in IM2 and IM3, although the cells began to detach from the bottom of the culture dish (Fig. 2).

We also performed immunostaining and RT-PCR for nervespecific marker expression after 48-72 hours of the induction. The results of immunostaining using the neuronal marker Tuj 1 and the astrocyte marker GFAP showed that all four AFSCs in each neurogenic induction medium expressed Tuj1 strongly and GFAP weakly (Fig. 3). A more extensive RT-PCR analysis was performed for other neural genes (Fig. 4). For AF1 cells, which

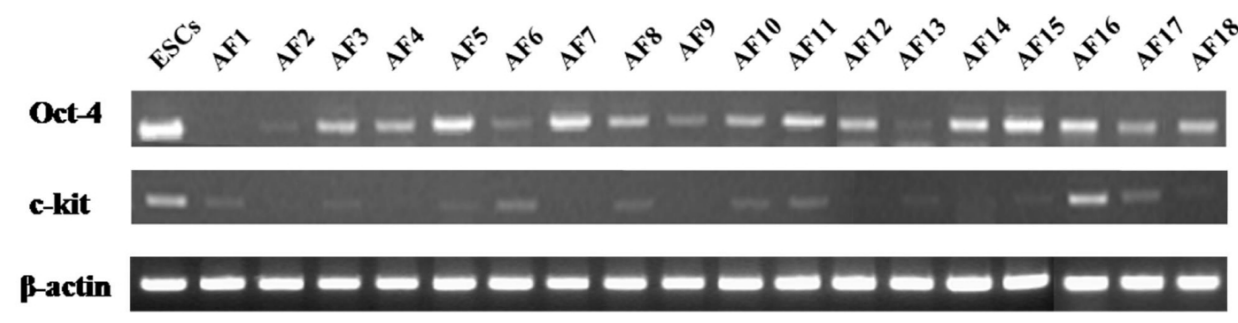

Fig. 1. Stem cell marker expression of amniotic fluid-derived stem cells (AFSCs). AFSCs express 0ct-4 and c-kit messenger RNA (mRNA). Reverse transcription-polymerase chain reaction (RT-PCR) analyses showed that 0ct-4 and c-kit mRNAs were expressed in cultured AFSCs (AF118), and the PCR product of $\beta$-actin served as an internal control (positive control with embryonic stem cells [ESCs]; 18 independent samples of cultured AFSCs). Oct-4 was negative in one sample (AF1), slightly positive in four samples (AF2, AF6, AF9, AF13), and positive in 13 samples (AF3-5, AF7-8, AF10-12, AF14-18). C-kit was negative in seven samples (AF2, AF4, AF7, AF9, AF12, AF14, AF18), slightly positive in 10 samples (AF1, AF3, AF5, AF6, AF8, AF10, AF11, AF13, AF15, AF17), and strongly positive in one sample (AF16). 
NC

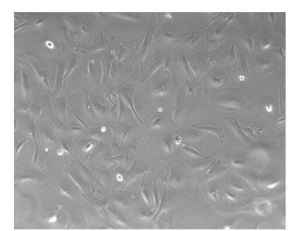

AF16

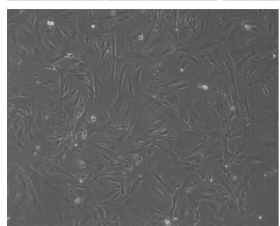

AF17

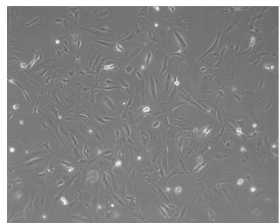

AF18

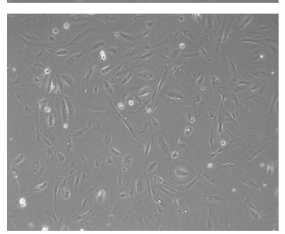

IM1
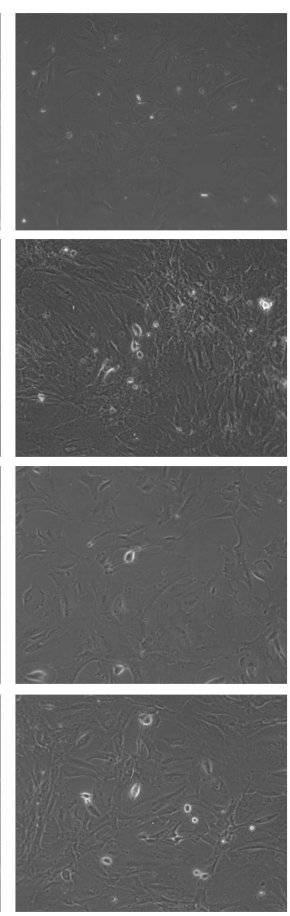

IM2
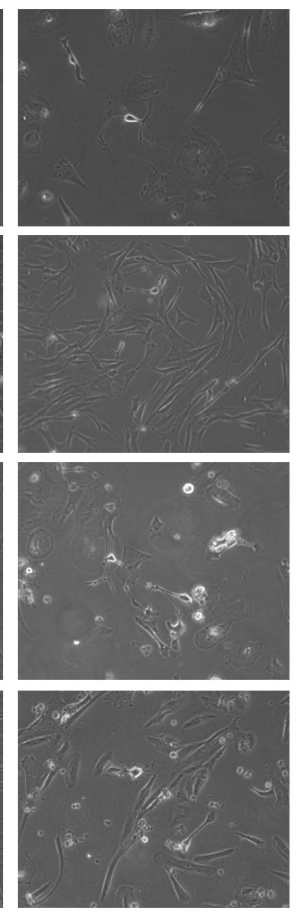
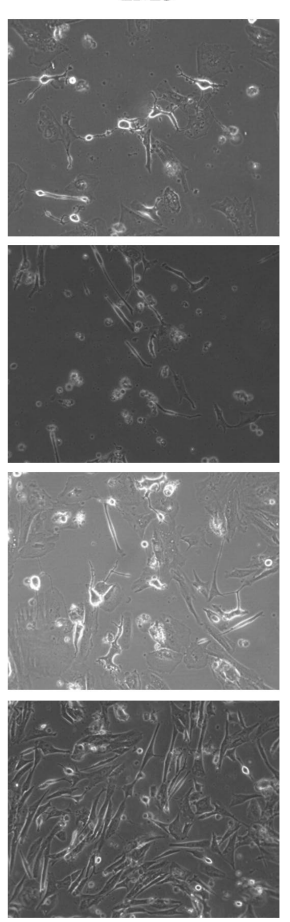

Fig. 2. Cell morphology following neuronal induction of amniotic fluid-derived stem cells (AFSCs). AFSCs grown under control medium (NC; negative control) showed fibroblastic morphology. On the second day of induction, cells grown in induction media (IM) 2 and IM3 showed more changed morphology than those grown in induction medium IM1. Cells in IM2 and IM3 showed cytoplasm retraction toward the nucleus and extended processes. Magnification, $100 \times$. were 0ct-4 $4^{-} \mathrm{c}-\mathrm{kit}^{\text {low }}$, IM2 induced the expression of the neuronal markers NF-M and trkA, whereas IM1 and IM3 did not induce any significant changes in the expression of neural markers. For AF16 cells, which were Oct- $4^{+} \mathrm{c}-\mathrm{kit}{ }^{+}$, all three media induced the expression of MAP2 (neuronal marker), NF-M, and tau (neuronal marker), and IM1 additionally induced the expression of MBP (oligodendrocyte marker), whereas IM2 and IM3 additionally induced the expression of GFAP, NSE (neuronal marker), and trkA. For AF17 cells, which were Oct- $4^{+} \mathrm{c}-\mathrm{kit}^{\text {low }}$, IM2 induced the expression of tau, and IM3 induced the expression of tau and MBP, whereas IM 1 did not induce any significant changes in the expression of neural markers. For AF18 cells, which were Oct- $4^{+} \mathrm{c}-\mathrm{kit}{ }^{-}, \mathrm{IM} 1$ induced the expression of NF-M, and IM2 induced the expression of NF-M, trkA, and MBP, whereas IM3 had no effect in the expression of neural markers. The summary of these results is displayed as Table 2 and suggests that AFSCs expressing both 0ct-4 and c-kit have the greatest potency for neurogenesis, and RA has little effect on the differentiation process.

Finally, to investigate whether the inability of RA to affect neurogenesis of AFSCS was due to a difference in retinoic acid receptor (RAR) expression, the expression levels of two RAR isoforms ( $\alpha$ and $\beta$ ) were analyzed. The expression of RAR $\alpha$ was different in all four individual samples, which ranged from low to high, and was increased in AF16 by IM2 and in AF18 by IM1 and IM2. The expression of RAR $\beta$ was low in AF1 and high in
IM1

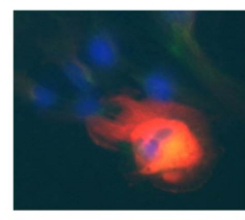

AF16
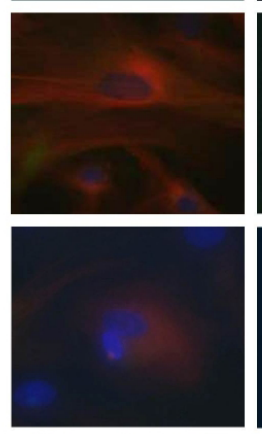

AF17

\section{AF1}
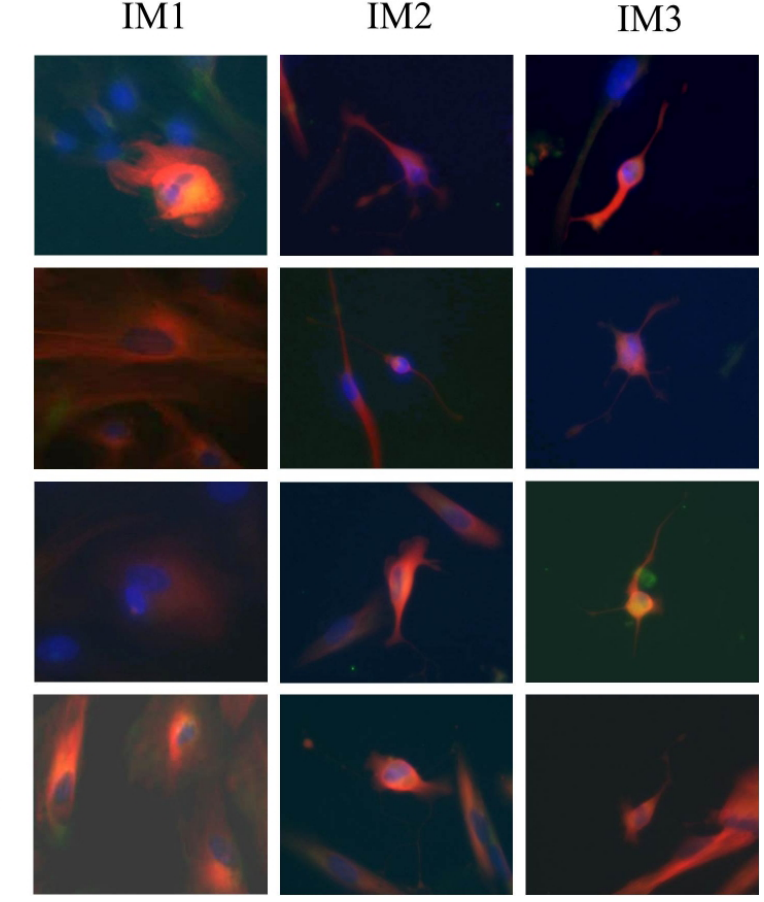

Fig. 3. Cellular expression of neural cell markers in induced amniotic fluid-derived stem cells (AFSCs). The neurally induced AFSCs were fixed and immunostained by incubation with primary antibodies directed against Tuj 1 (red) and glial fibrillary acidic protein (GFAP; green), followed by incubation with fluorescein isothiocyanate- or Cy3-conjugated secondary antibodies. The cells were counterstained with DAPI (blue). All four AFSC samples in each neurogenic induction medium expressed Tuj1 (neuronal marker) strongly and GFAP weakly. Cells induced in induction media (IM) 2 and IM3 showed retracted cell body toward the nucleus and extended processes. Magnification, $400 \times$. 


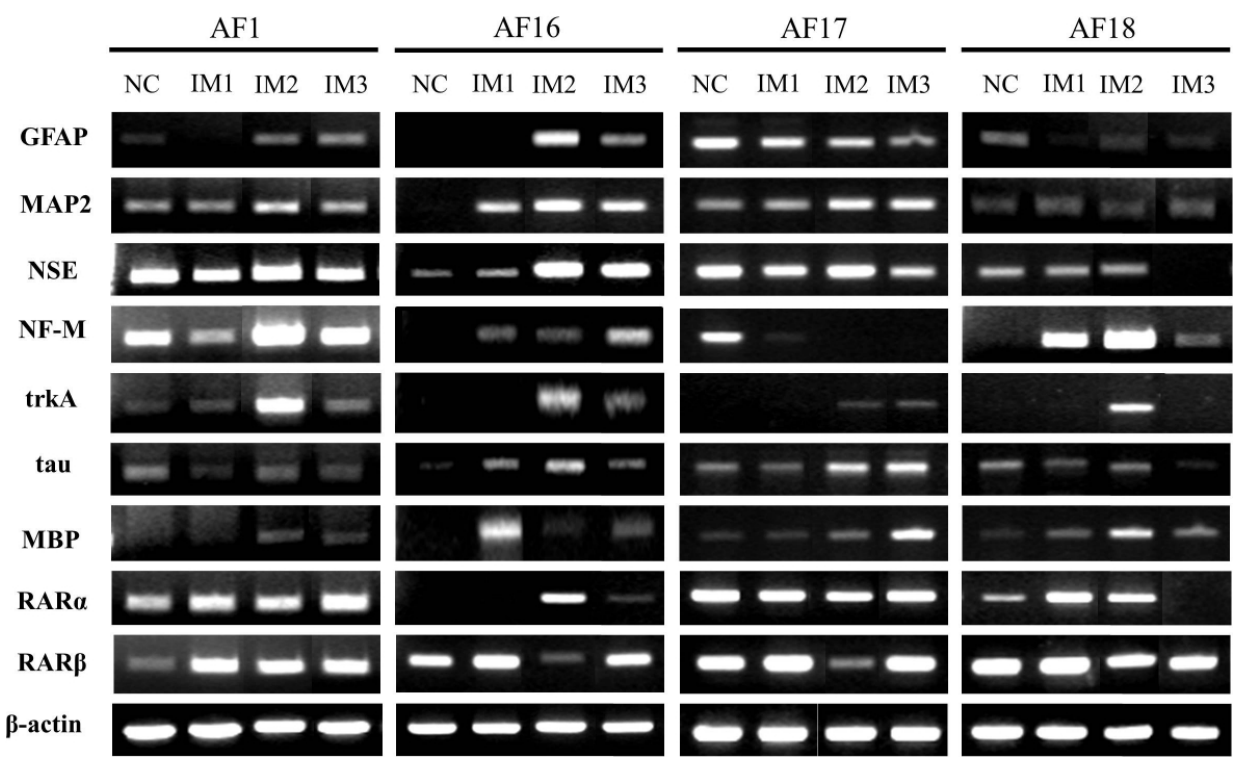

Fig. 4. Reverse transcription-polymerase chain reaction result for neural cell markers in cells grown in various induction media (IM). The neurally induced amniotic fluidderived stem cells were harvested and the total cellular RNAs were isolated, followed by reverse transcription to cDNAs. Polymerase chain reaction was performed using the specific primer pairs for the indicated genes. NC, negative control (uninduced cells); IM1, control medium with all-trans retinoic acid (RA); IM2, control medium with neuromix (insulin, indomethacin, and IBMX); IM3, control medium with all-trans RA plus neuromix.

Table 2. Summary of RT-PCR for expression of neural markers in Fig. 4

\begin{tabular}{ccccc}
\hline & AF1 & AF16 & AF17 & AF18 \\
\hline Stem cell marker expression & & & & + \\
Oct-4 & - & + & Low & - \\
c-kit & Low & & - & NF-M \\
Expressed neural markers & & NF-M, MAP2, tau, MBP & NF-M, trkA, MBP \\
IM1 & - & NF-M, MAP2, tau, trkA, & tau \\
IM2 & NF-M, trkA & GFAP, NSE & tau, MBP \\
IM3 & NF-M & NF-M, MAP2, tau, trkA, & - \\
\end{tabular}

RT-PCR, reverse transcription-polymerase chain reaction; IM, induction media.

the other cells, and was increased in AF1 by all of the IM, and decreased in AF16 and AF17 by IM2 (Fig. 4). These results indicate that there was no correlation of RAR with RA effects on the expression of neural markers, implying that the lack of effects by RA on neurogenesis of AFSCs was not due to RAR expression.

\section{Discussion}

Oct-4 is an important transcription factor as a marker of pluripotent stem cells to maintain the totipotency of ESCs, which disappears rapidly when cells have differentiated [14]. The protein-tyrosine kinase c-kit is also a stem cell-specific factor that is important in gametogenesis, melanogenesis, and hematopoiesis [15], and is present on human ESCs and primordial germ cells as well as many somatic stem cells [1618]. Previous reports have shown that Oct-4 messenger RNA (mRNA) expression is low and Oct-4-positive cells are very weak in amniotic fluid $[19,20]$, and c-kit expression was detected in about 1\% of cultured amniotic fluid cell populations [2]. In our study, the levels of Oct-4 and c-kit mRNA expression in the AFSCs showed variability sample by sample, as Oct- 4 mRNAs were positive in 17 of 18 AFSC samples and c-kit mRNAs were expressed in 11 of 18 AFSC samples (Fig. 1). We hypothesized that the different expression levels of Oct-4 and c-kit might be caused by either different initial populations of stem/progenitor cells or different cell concentrations. Further studies will be needed to evaluate individual differences of the isolated AFSCs.

In this study, we attempted to evaluate three different kinds of neurogenesis-inducing media, composed of RA and/or neuromix, for neurogenesis of AFSCs. RA is known to affect neurons in ESCs and umbilical cord blood cells at various stages of differentiation, including causing the outgrowth of more and longer neurites than would normally be observed [21] and inducing changes in cell morphology and the expression of RARs as well as neural-specific markers [22]. Neuromix, composed of IBMX, indomethacin, and insulin, was used in the 
neuronal differentiation of ADSCs. With neuromix, about 20$25 \%$ of the ADSCs were differentiated into cells with typical neural morphological characteristics, accompanied by increased expression of NSE, vimentin, and the nerve growth factor receptor trkA [23]. IBMX, a phosphodiesterase inhibitor, causes the elevation of intracellular cyclic adenosine monophosphate (cAMP), which is a neural stimulus for various cell types, including mesenchymal stem cells (MSCs) [24]. Indomethacin, an inhibitor of cyclooxygenase, promotes neural cell survival after ischemic injury in the central nervous system [25]. Insulin promotes the maturation of differentiating neocortical cells in rat brains [26].

Our neurogenesis results, using the three different combinations of neural IM, showed that the AFSCs had similar morphological changes and immunofluorescent staining results, irrespective of their Oct-4 and c-kit expression (Figs. 2 and 3), but had different mRNA expression profiles (Fig. 4). The cell morphology changed according to neuronal induction, where neuromix was more effective than RA. In the RT-PCR results, the number of upregulated neural markers was increased by the neuromix-containing IM but not by the medium containing RA only. RAR $\alpha$ and RAR $\beta$, the two RAR receptor isoforms, were expressed differently in each induction group of AFSCs. RAR $\alpha$ / $\beta$ are known to be upregulated in human cord blood-derived $\mathrm{CD}_{133^{+}}$hematopoietic stem cells when undergoing neuronal induction [22]; however, this was not seen in the AFSCs in this study. It seems that RA and neuromix did not significantly affect the expression of RAR $\alpha / \beta$ during neuronal induction of AFSCs.

Taking the cell morphology changes and RT-PCR results together, RA had little influence on AFSCs as compared with neuromix; thereby, there were few morphological changes and low mRNA expression of neural cell-specific markers. The result that neuromix is more effective than RA at inducing neuronal differentiation of AFSCs, even though our IM had other ingredients (e.g., indomethacin and insulin), is similar to that seen in placenta-derived multipotent cells (PDMCs) and MSCs derived from human umbilical cord blood (MSC ${ }^{\text {hUCB }}$ ) $[24,27]$. Accordingly, the improved effect seen with neuromix in AFSCs might show that these cells are more similar to MSCs, such as PDMCs and MSC ${ }^{\text {hUCB }}$, than ESCs. Therefore, the efficiency of neuronal induction in AFSCs could be different according to the ingredients used in the IM.

Oct-4- and c-kit-positive cells also showed much more upregulated neural markers than c-kit-low or -negative cells. Therefore, we hypothesized that c-kit expression, rather than 0ct-4 expression, affects neural marker expression in neurogenesis of AFSCs (Table 2). C-kit is expressed in the nervous system and in nervous system tumors [28], and stem cell factor to c-kit signaling has a role in neural development [29]. Furthermore, Das et al. [30] reported that c-kit was related to Notch signaling in differentiation in a variety of tissues, including those of the central nervous system. Therefore, c-kit expression might be related to neural differentiation of AFSCs, and its mechanism should be studied further.

There are limited data and methods relevant to the differentiation of stem cells into specialized cell types in vitro or in vivo (at cell transplantation). Although our study demonstrates that AFSCs can change morphologically into neural-like cells and induce cells to express neural markers, further elucidation of the molecular mechanisms involved is needed to decrease the individual differences of isolated AFSCs and increase the efficiency of neural differentiation for therapeutic applications. Further mechanistic insights into neurogenesis in vitro with high efficiency might promote the generation of functionally appropriate neural cells in the future that could be used in cell therapies for neurodegenerative diseases.

\section{Acknowledgements}

This study was supported by Samsung Biomedical Research Institute Grant (SMX1132441), and the Basic Science Research Program through the National Research Foundation of Korea (NRF) funded by the Ministry of Education, Science and Technology (NRF-2012R1A1A2006803).

\section{References}

1. Smith AG. Embryo-derived stem cells: of mice and men. Annu Rev Cell Dev Biol 2001;17:435-62.

2. De Coppi P, Bartsch G Jr, Siddiqui MM, Xu T, Santos CC, Perin L, et al. Isolation of amniotic stem cell lines with potential for therapy. Nat Biotechnol 2007;25:100-6.

3. Cipriani S, Bonini D, Marchina E, Balgkouranidou I, Caimi L, Grassi Zucconi G, et al. Mesenchymal cells from human amniotic fluid survive and migrate after transplantation into adult rat brain. Cell Biol Int 2007;31:845-50.

4. Zuk PA, Zhu M, Mizuno H, Huang J, Futrell JW, Katz AJ, et al Multilineage cells from human adipose tissue: implications for cellbased therapies. Tissue Eng 2001;7:211-28.

5. Marcus AJ, Woodbury D. Fetal stem cells from extra-embryonic tissues: do not discard. J Cell Mol Med 2008;12:730-42. 
6. Murphy SV, Atala A. Amniotic fluid stem cells. In: Cetrulo KJ, ed. Perinatal stem cells. 2nd ed. Hoboken, NJ: Wiley-Blackwell, 2013:115.

7. Gosden CM. Amniotic fluid cell types and culture. Br Med Bull 1983;39:348-54.

8. Prusa AR, Marton E, Rosner M, Bernaschek G, Hengstschläger M. Oct4-expressing cells in human amniotic fluid: a new source for stem cell research? Hum Reprod 2003;18:1489-93.

9. Di Trapani M, Bassi G, Fontana E, Giacomello L, Pozzobon M, Guillot $P V$, et al. Immune regulatory properties of CD117(pos) amniotic fluid stem cells vary according to gestational age. Stem Cells Dev 2015;24:132-43.

10. Maden M. Retinoic acid in the development, regeneration and maintenance of the nervous system. Nat Rev Neurosci 2007;8:75565.

11. Jones-Villeneuve EM, McBurney MW, Rogers KA, Kalnins VI. Retinoic acid induces embryonal carcinoma cells to differentiate into neurons and glial cells. J Cell Biol 1982;94:253-62.

12. Guan $K$, Chang $H$, Rolletschek $A$, Wobus AM. Embryonic stem cellderived neurogenesis. Retinoic acid induction and lineage selection of neuronal cells. Cell Tissue Res 2001;305:171-6.

13. Kim HK, Im EH, Park H, Cho JA, Yang DY, Kim KH, et al. Characterization and differentiation into adipocytes of mesenchymal stem cells (MSCs) from human adipose tissue and amniotic fluid. Korean J Obstet Gynecol 2009;52:447-55.

14. Donovan PJ. High Oct-ane fuel powers the stem cell. Nat Genet 2001;29:246-7

15. Fleischman RA. From white spots to stem cells: the role of the Kit receptor in mammalian development. Trends Genet 1993;9:285-90.

16. Hoffman LM, Carpenter MK. Characterization and culture of human embryonic stem cells. Nat Biotechnol 2005;23:699-708.

17. Crane JF, Trainor PA. Neural crest stem and progenitor cells. Annu Rev Cell Dev Biol 2006;22:267-86.

18. Guo CS, Wehrle-Haller B, Rossi J, Ciment G. Autocrine regulation of neural crest cell development by steel factor. Dev Biol 1997;184:61-9.

19. Peng HH, Wang $T H$, Chao AS, Chang SD. Isolation and differentiation of human mesenchymal stem cells obtained from second trimester amniotic fluid; experiments at Chang Gung Memorial Hospital.
Chang Gung Med J 2007;30:402-7.

20. McLaughlin D, Tsirimonaki E, Vallianatos G, Sakellaridis N, Chatzistamatiou T, Stavropoulos-Gioka C, et al. Stable expression of a neuronal dopaminergic progenitor phenotype in cell lines derived from human amniotic fluid cells. J Neurosci Res 2006;83:1190-200.

21. Maden M. Retinoid signalling in the development of the central nervous system. Nat Rev Neurosci 2002;3:843-53.

22. Jang YK, Park JJ, Lee MC, Yoon BH, Yang YS, Yang SE, et al. Retinoic acid-mediated induction of neurons and glial cells from human umbilical cord-derived hematopoietic stem cells. J Neurosci Res 2004;75:573-84.

23. Ashjian PH, Elbarbary AS, Edmonds B, DeUgarte D, Zhu M, Zuk PA, et al. In vitro differentiation of human processed lipoaspirate cells into early neural progenitors. Plast Reconstr Surg 2003;111:1922-31.

24. Yen BL, Chien CC, Chen YC, Chen JT, Huang JS, Lee FK, et al. Placentaderived multipotent cells differentiate into neuronal and glial cells in vitro. Tissue Eng Part A 2008;14:9-17.

25. Asanuma M, Nishibayashi-Asanuma S, Miyazaki I, Kohno M, Ogawa N. Neuroprotective effects of non-steroidal anti-inflammatory drugs by direct scavenging of nitric oxide radicals. J Neurochem 2001;76:1895-904.

26. Plitzko D, Rumpel S, Gottmann K. Insulin promotes functional induction of silent synapses in differentiating rat neocortical neurons. Eur J Neurosci 2001;14:1412-5.

27. Tio $M$, Tan $K H$, Lee $W$, Wang $\Pi$, Udolph $G$. Roles of db-cAMP, IBMX and $R A$ in aspects of neural differentiation of cord blood derived mesenchymal-like stem cells. PLoS One 2010;5:e9398.

28. Hamel $W$, Westphal $M$. The road less travelled: c-kit and stem cell factor. J Neurooncol 1997;35:327-33.

29. Hirata $T_{1}$ Morii $E_{1}$ Morimoto $M$, Kasugai T, Tsujimura T, Hirota $S_{\text {, et al. }}$ Stem cell factor induces outgrowth of c-kit-positive neurites and supports the survival of c-kit-positive neurons in dorsal root ganglia of mouse embryos. Development 1993;119:49-56.

30. Das $A \bigvee$, James J, Zhao $X$, Rahnenführer J, Ahmad I. Identification of c-Kit receptor as a regulator of adult neural stem cells in the mammalian eye: interactions with Notch signaling. Dev Bio 2004;273:87-105 